\title{
Epidermal growth factor receptor mutation subtype has differential effects on adjuvant chemotherapy for resected adenocarcinoma pathological stages II-III
}

\author{
YOHEI KAWAGUCHI ${ }^{*}$, TETSUYA OKANO $^{1 *}$, KENTARO IMAI $^{1}$, SACHIO MAEHARA ${ }^{1}$, \\ JUNICHI MAEDA ${ }^{1}$, KOICHI YOSHIDA ${ }^{1}$, MASARU HAGIWARA ${ }^{1}$, MASATOSHI KAKIHANA ${ }^{1}$, \\ NAOHIRO KAJIWARA $^{1}$, TATSUO OHIRA ${ }^{1}$, JUN MATSUBAYASHI ${ }^{2}$ and NORIHIKO IKEDA ${ }^{1}$ \\ ${ }^{1}$ Department of General Thoracic Surgery, Tokyo Medical University Hospital; \\ ${ }^{2}$ Department of Anatomic Pathology, Tokyo Medical University, Tokyo 1600023, Japan
}

Received April 18, 2019; Accepted September 25, 2019

DOI: $10.3892 / \mathrm{ol} .2019 .11050$

\begin{abstract}
The aim of the present study was to investigate epidermal growth factor receptor $(E G F R)$ mutations as a prognostic factor for postoperative patients with positive $E G F R$ mutations treated with postoperative platinum-based adjuvant chemotherapy (PBAC), and whether two common $E G F R$ mutations exhibit different responses to PBAC. A total of 110 patients who underwent complete surgical resection were enrolled, and overall survival (OS) and disease-free survival (DFS) were investigated based on EGFR mutation status and PBAC. The 3 year OS rate in patient groups were as follows: Patients with EGFR mutations (MT) undergoing PBAC, 89.3\%; MT patients without PBAC, 83.3\%; wild-type (WT) patients with PBAC, $82.3 \%$; and WT patients without PBAC, $62.2 \%$. Statistically significant differences were observed between WT patients based on PBAC $(\mathrm{P}=0.026)$. No statistically significant differences were observed between MT patients with PBAC and MT patients without PBAC. On the basis of mutation subtypes, the 3 year OS rate of patient groups were as follows: Patients with in-frame deletions in exon19 (19 del) with PBAC, 92.3\%; patients with 19 del without PBAC, 85.7\%; patients with the point mutation
\end{abstract}

Correspondence to: Dr Tetsuya Okano, Department of General Thoracic Surgery, Tokyo Medical University Hospital, 6-7-1 Nishishinjuku, Shinnjuku-ku, Tokyo 1600023, Japan

E-mail: tokano@tokyo-med.ac.jp

*Contributed equally

Abbreviations: CT, computed tomography; DFS, disease-free survival; EGFR, epidermal growth factor receptor; NSCLC, nonsmall-cell lung cancer; OS, overall survival; PBAC, platinum-based adjuvant chemotherapy; TKI, tyrosine kinase inhibitors; WT, wild-type

Key words: epidermal growth factor receptor mutation, platinum-based adjuvant chemotherapy, mutation subtypes, lung adenocarcinoma
L858R inexon21 (21L858R) with PBAC, 86.7\%; and patients with 21L858R without PBAC, $81.5 \%$; the respective 3-year DFS rates were $53.8,14.3,40.2$ and $26.9 \%$. Statistically significant differences were observed in the DFS rates in 19 del patients, which was dependent on PBAC $(\mathrm{P}=0.040)$. $E G F R$ mutation-positive patients exhibited a decreased benefit from PBAC for increasing in survival rate compared with WT patients. It may be necessary to consider postoperative strategies based on EGFR mutations and their subtype in the future.

\section{Introduction}

The best therapeutic modality for clinical stages I, II, and appropriate stage IIIA non-small-cell lung cancer (NSCLC) is complete surgical resection $(1,2)$. However, despite improvements in diagnostic and therapeutic approaches, only $60 \%$ of patients survive 5 years after surgery (1).

To improve the survival rates, the first trial of adjuvant chemotherapy was performed decades ago (1). Subsequently, randomized trials reported the benefit of platinum-based adjuvant chemotherapy (PBAC) in patients with pathologic stages II and III NSCLC with lymph node involvement, and subset analyses suggested a benefit in patients with large IB tumors (3-5). However, the 5 year overall survival (OS) advantage for patients who underwent adjuvant chemotherapy was reported to be a modest 5.4\% (6). Furthermore, PBAC often causes adverse events. Several randomized trials of adjuvant chemotherapy for NSCLC have reported that almost $30 \%$ of patients experienced grade III or IV toxicity and there were $0.8-2.0 \%$ of adjuvant chemotherapy-related deaths (7). Thus, its significant toxicity may limit its use.

On the basis of the above, it is very important to adapt adjuvant chemotherapy and to identify useful factors predicting its efficacy.

Mutations in the epidermal growth factor receptor $(E G F R)$, most of which have been detected in lung adenocarcinoma, are predictors of response to EGFR tyrosine kinase inhibitors (TKIs), which have proven efficacy in the treatment of advanced stage NSCLC $(8,9)$. 
Although EGFR mutations are prognostic factors in only unresectable advanced NSCLC, there are few reports of their utility as prognostic factors in resectable NSCLC (10). In particular, there are no studies in the context of predictive factors for PBAC effects.

EGFR mutations are categorized into two groups, common mutations and minor mutations. Common mutations comprise $85 \%$ of all $E G F R$ mutations and include two subtypes, in-frame deletions in exon19 (19 del) and the point mutation L858R in exon21 (21L858R) (11). Those two mutations are expected to have different biological features $(11,12)$.

Here, we investigated $E G F R$ mutations as prognostic factors in postoperative $E G F R$ mutation-positive (MT) patients treated with PBAC and whether the above two common mutations are associated with differential responses to PBAC.

\section{Materials and methods}

Patient selection and study design. A total of 720 consecutive patients with adenocarcinoma underwent pulmonary resection with no evidence of residual cancer either macroscopically or microscopically between January 2009 and December 2013 at Tokyo Medical University Hospital. Of these, 171 patients in pathological stages II and III (per the 7th Edition of the TNM Classification for Lung and Pleural Tumors of the Union for International Cancer Control) were enrolled (13). We excluded 45 patients because they had received preoperative chemotherapy, radiotherapy, or both; because their tumors had a mutation in $E G F R$ exon20 (an indicator of resistance to EGFR-TKIs), mutations in the echinoderm microtubule-associated protein-like 4-anaplastic lymphoma kinase fusion gene, or other minor mutations; or because the presence of EGFR mutations could not be analyzed. We also excluded 10 patients who had received adjuvant chemotherapy other than platinum-based regimens such as uracil-tegafur or tegafur-gimeracil-oteracil and six patients who received only the best supportive care including palliative radiotherapy for controlling pain from bone metastasis as lung cancer recurrence and no treatments such as radiotherapy, chemotherapy, or surgical treatment after disease recurrence. We enrolled the remaining 110 patients in the study. The study followed a retrospective, single institutional design and investigated $E G F R$ mutation subtype in patients who had undergone surgical resection of adenocarcinoma. This study was approved by the ethics committee of the Tokyo Medical University; the approval number is 2016-167.

Analysis of patients. We reviewed the medical records of patients to assess the following clinicopathological information: Age; sex; smoking history; surgical procedures; tumor differentiation; blood vessel invasion; lymphatic permeation; visceral pleural invasion; EGFR mutation status; PBAC regimen; OS defined as the time elapsed from the date of surgery to the date of death; and disease-free survival (DFS) defined as the time elapsed from the date of pulmonary resection to the date of initial recurrence or death.

We divided the patients into a mutation (MT) group and a wild-type (WT) group based on their EGFR status and analyzed their prognosis.

After surgical resection, the patients were examined at 3 month intervals for 3 years, then at 6 month intervals for the next 2 years, and thereafter at 1 year intervals. The systemic evaluations of patients included physical examinations, chest roentgenograms, chest and abdominal computed tomography (CT) scans, and tumor marker measurement. Brain magnetic resonance imaging and bone scintigraphy or positron emission tomography/CT scanning was performed every year.

$E G F R$ mutation analysis. All of the surgical specimens collected were fixed in $10 \%$ formalin and embedded in paraffin. Representative sections were routinely stained with hematoxylin and eosin. Experienced pathologists reviewed the samples to confirm that the sections contained carcinoma cells. EGFR mutation analysis of the histology specimens was screened using the direct sequencing method until October 2009. Direct sequencing method has a detection sensitivity of around $25 \%$, while the cycleave polymerase chain reaction method is around 1 to $5 \%$. So we use cycleave polymerase chain reaction method (after November 2009), as previously described $(14,15)$.

Statistical analysis. OS and DFS were estimated using the Kaplan-Meier method. Differences in survival rates were determined using log-rank analysis. Hazard ratios and their 95\% confidence intervals were calculated using the Cox proportional hazards model to determine independent predictors of the OS and DFS. Significance differences among the categorized groups were compared using Chi-square tests. $\mathrm{P}<0.05$ was considered to indicate a statistically significant difference. Statistical analyses were performed using the software package SPSS (version 24.0; SPSS, Inc.).

\section{Results}

Patient demographics. The median follow-up period for all of the patients was 35.9 months (range, 0.27-88.5 months). Characteristics of the patients are summarized in Table I. PBAC was carried out in 62 patients $(56.4 \%)$. The most common regimen of the PBAC comprised cisplatin and vinorelbine (41 of $62 ; 66.1 \%$ ), and other regimens were as described in Table I. Forty-eight patients (of 110 patients; 44\%) did not received adjuvant chemotherapy. The most common reason was the patient's comorbidity such as renal dysfunction, etc. The second most common reason was the patient's preference. Another one was elder and poor performance status.

Among the 110 patients, $63(57.2 \%)$ patients had confirmed recurrence. EGFR mutations were detected in 50 patients (45.6\%), and the most common EGFR mutation was L858R ( 29 of $50 ; 58.0 \%$ ). The second most common mutation was 19 del (21 of 50; 40.2\%).

The differences between patients in the PBAC group and those in the observation group are shown in Table II. Statistically significant differences in age were found between the two groups $(\mathrm{P}<0.001)$. In the PBAC group, five patients (of 62 patients; $8 \%$ ) were over 75 years old. In the observation group, 17 patients (of 48 patients; $35 \%$ ) were over 75 years old. There were no statistically significant differences in the other clinicopathological factors between the groups.

Prognostic outcomes. Survival time was investigated on the basis of EGFR mutation status and PBAC status. DFS curves stratified on the basis of EGFR and PBAC status are shown 
Table I. Patient characteristics $(n=110)$.

\begin{tabular}{|c|c|}
\hline Variables & Value $(\%)$ \\
\hline \multicolumn{2}{|l|}{ Sex } \\
\hline Men & $64(58)$ \\
\hline Women & $46(42)$ \\
\hline \multicolumn{2}{|l|}{ Age (years) } \\
\hline Median age & 66 \\
\hline Range & $40-88$ \\
\hline \multicolumn{2}{|l|}{ Smoking habits } \\
\hline Ever-smoker/unknown & $51(46)$ \\
\hline Never smoker & $59(54)$ \\
\hline \multicolumn{2}{|l|}{ Surgical procedure } \\
\hline Lobectomy & 109 (99) \\
\hline Segmentectomy & $1(1)$ \\
\hline \multicolumn{2}{|l|}{ Pathological stage } \\
\hline II & $52(47)$ \\
\hline III & $58(53)$ \\
\hline \multicolumn{2}{|l|}{ Vascular invasion } \\
\hline Positive & $86(78)$ \\
\hline \multicolumn{2}{|l|}{ Lymphatic permeation } \\
\hline Positive & $98(89)$ \\
\hline \multicolumn{2}{|l|}{ Viscreral visceral pleural invasion } \\
\hline Positive & $47(43)$ \\
\hline \multicolumn{2}{|l|}{ Tumor differentiation } \\
\hline Poor & $31(28)$ \\
\hline Well/Moderate & $79(72)$ \\
\hline \multicolumn{2}{|l|}{ Adjuvant chemotherapy } \\
\hline PBAC & $62(56)$ \\
\hline None & $48(44)$ \\
\hline \multicolumn{2}{|l|}{ Tumor recurrence } \\
\hline Recurrence & $63(57)$ \\
\hline Non-recurrence & $47(43)$ \\
\hline \multicolumn{2}{|l|}{ EGFR mutation status } \\
\hline Mutant; Exon 19/21 & $\begin{array}{c}50(45) ; \\
21(19) / 29(26)\end{array}$ \\
\hline Wild-type & $60(55)$ \\
\hline \multicolumn{2}{|l|}{ PBAC regimen } \\
\hline Cisplatin + Vinorelbine & $41(37)$ \\
\hline Cisplatin + Gemcitabine & $1(1)$ \\
\hline Cisplatin + tegafur/gimeracil/oteracil & $1(1)$ \\
\hline Cisplatin + Docetaxel & $7(6)$ \\
\hline Cisplatin + Pemetrexed & $1(1)$ \\
\hline Carboplatin + Gemcitabine & $8(7)$ \\
\hline Carboplatin + Paclitaxel & $3(3)$ \\
\hline Observation & $48(44)$ \\
\hline
\end{tabular}

EGFR, epidermal growth factor receptor; PBAC, platinum-based adjuvant chemotherapy.

in Fig. 1A and B. The 3 year DFS rates in the groups were as follows: MT with PBAC, 46.5\%; MT without PBAC, $22.5 \%$;
Table II. Patient characteristics based on PBAC status.

\begin{tabular}{|c|c|c|c|}
\hline \multirow[b]{2}{*}{ Variables } & \multicolumn{2}{|c|}{$\begin{array}{l}\text { PBAC status, } \\
\mathrm{n}(\%)\end{array}$} & \multirow[b]{2}{*}{ P-value } \\
\hline & $\begin{array}{l}\text { PBAC } \\
(n=62)\end{array}$ & $\begin{array}{l}\text { None } \\
(n=48)\end{array}$ & \\
\hline Sex & & & 0.112 \\
\hline Men & $32(29)$ & $32(29)$ & \\
\hline Women & $30(27)$ & $16(15)$ & \\
\hline Age, years & & & $<0.001$ \\
\hline$<75$ & $57(52)$ & $31(28)$ & \\
\hline$\geq 75$ & $5(1)$ & $17(15)$ & \\
\hline Smoking habits & & & 0.774 \\
\hline Ever-smoker/unknown & $34(31)$ & $25(23)$ & \\
\hline Never smoker & $28(25)$ & $23(21)$ & \\
\hline Surgical procedure & & & 0.377 \\
\hline Lobectomy & $61(55)$ & $48(44)$ & \\
\hline Segmentectomy & $1(1)$ & 0 & \\
\hline Pathological stage & & & 0.097 \\
\hline II & $25(23)$ & $27(25)$ & \\
\hline III & $37(34)$ & $21(19)$ & \\
\hline Vascular invasion & & & 0.477 \\
\hline Present & $50(45)$ & $36(33)$ & \\
\hline Absent & $12(11)$ & $12(11)$ & \\
\hline Lymphatic permeation & & & 0.088 \\
\hline Present & $58(53)$ & $40(36)$ & \\
\hline Absent & $4(3)$ & $8(8)$ & \\
\hline $\begin{array}{l}\text { Viscreralvisceral pleural } \\
\text { invasion }\end{array}$ & & & 0.333 \\
\hline Present & $24(22)$ & $23(21)$ & \\
\hline Absent & $38(34)$ & $25(23)$ & \\
\hline Tumor differentiation & & & 0.840 \\
\hline Poor & $17(15)$ & $14(13)$ & \\
\hline Well/Moderate & $45(41)$ & $34(31)$ & \\
\hline Tumor recurrence & & & 0.562 \\
\hline Recurrence & $37(34)$ & $26(23)$ & \\
\hline Non-recurrence & $25(23)$ & $22(20)$ & \\
\hline$E G F R$ mutation status & & & 0.752 \\
\hline Mutant & $29(26)$ & $21(19)$ & \\
\hline Wild-type & $33(30)$ & $27(25)$ & \\
\hline
\end{tabular}

PBAC, platinum-based adjuvant chemotherapy; EGFR, epidermal growth factor receptor.

WT with PBAC, 57.1\%; and WT without PBAC, 47.1\%; there were no statistically significant differences among them.

The OS curves stratified on the basis of EGFR and PBAC status are shown in Fig. $1 \mathrm{C}$ and D. The 3 year OS rates in the groups were as follows: MT with PBAC, $89.3 \%$; MT without PBAC, 83.3\%; WT with PBAC, 82.3\%; WT without PBAC, $62.2 \%$; Fig. 1D shows statistically significant differences in OS of WT patients with PBAC and that of WT patients without 
A

DFS stratified according to PBAC with MT patients

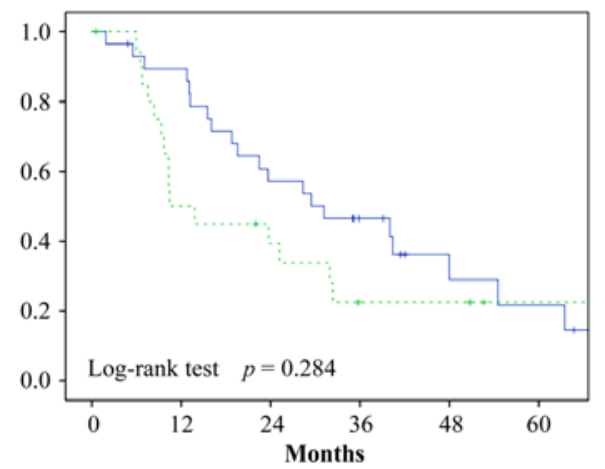

Patients at risk

$\begin{array}{llllllll}\text { PBAC } & 29 & 26 & 17 & 14 & 11 & 10\end{array}$

C

OS stratified according to PBAC with MT patients

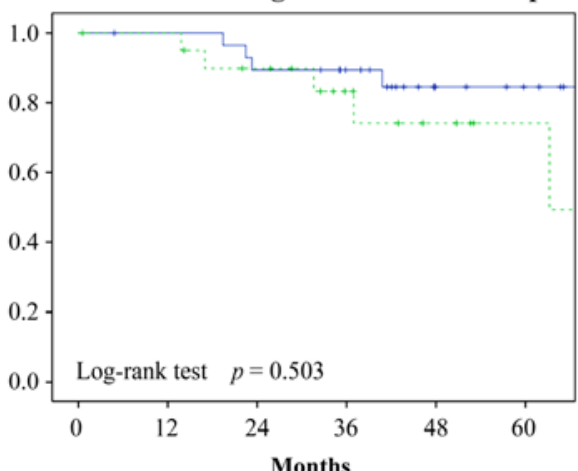

Patients at risk

PBAC

$29 \quad 29$

26

26

$25 \quad 25$

......... Observation

$21 \quad 21$

19

$\begin{array}{lll}18 & 17\end{array}$

B

DFS stratified according to PBAC with WT patients

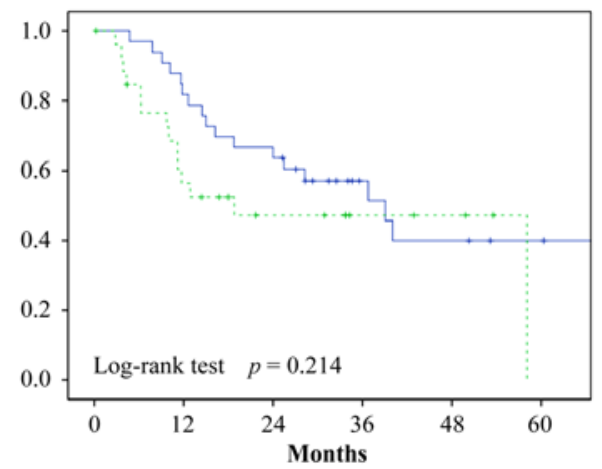

Patients at risk

\begin{tabular}{|c|c|c|c|c|c|c|}
\hline & PBAC & 33 & 27 & 21 & 19 & 16 \\
\hline ........... & Observation & 27 & 16 & 14 & 14 & 14 \\
\hline
\end{tabular}

D

OS stratified according to PBAC with WT patients

Patients at risk

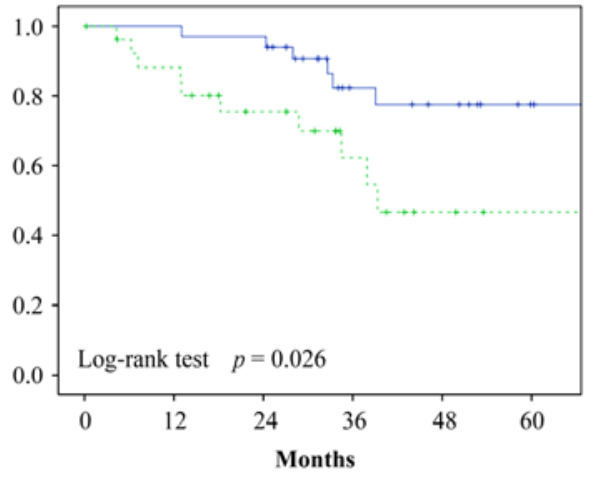

$\begin{array}{llllllll}\text { PBAC } & 33 & 33 & 32 & 28 & 27 & 27\end{array}$

$\begin{array}{llllllll}\text {......... Observation } & 27 & 24 & 21 & 19 & 17 & 17\end{array}$

Figure 1. Disease-free survival curves based on (A) PBAC in EGFR MT patients and (B) PBAC in EGFR mutation WT patients. There were no significant statistically differences between MT patients with PBAC and MT patients without PBAC. Overall survivalcurves based on (C) MT patients with PBAC and (D) WT patients with PBAC. PBAC, platinum-based adjuvant chemotherapy; EGFR, epidermal growth factor receptor; MT, mutation-positive; WT, wild-type.

PBAC $(\mathrm{P}=0.026)$. There were no statistically significant differences between MT patients with PBAC and MT patients without PBAC $(\mathrm{P}=0.503)$.

We also examined OS and DFS of the patients with mutants stratified per mutational subtypes (Fig. 2). The 3 year DFS of the patients in the stratified groups was as follows: 19 del with PBAC, 53.8\%; 19 del without PBAC, 14.3\%; 21L858R with PBAC, $40.2 \%$; and 21L858R without PBAC, $26.9 \%$.

The 3 year OS rates of the above groups of patients were as follows: 19 del with PBAC, 92.3\%; 19 del without PBAC, 85.7\%; 21L858R with PBAC, 86.7\%; and 21L858R without PBAC, $81.5 \%$. Statistical analysis of patients with 19 del revealed that there were statistically significant differences in their DFS rates, dependent on PBAC being carried out $(\mathrm{P}=0.040)$. On the other hand, there were no statistically significant differences in their OS rates $(\mathrm{P}=0.208)$. Statistical analysis of patients with 21L858R found no statistically significant differences in OS $(\mathrm{P}=0.981)$ or DFS $(\mathrm{P}=0.844)$.

There were no statistical difference about DFS in patients with 19 del according to drugs combination of PBAC $(\mathrm{P}=0.99)$.

Risk factors for poor prognosis. The potential risk factors for DFS and OS were analyzed using univariate survival analysis based on mutational status (Table III). In MT patients, univariate survival analysis showed that blood vessel invasion was the only risk factor associated with DFS (HR, 2.781; CI, 1.140-6.783; $\mathrm{P}=0.025)$. On the other hand, there were no significant risk factors associated with OS. In WT patients, the potential risk factors associated with OS were visceral pleural invasion (HR, 3.326; CI, 1.202-9.207; $\mathrm{P}=0.021$ ) and PBAC (HR, 3.005; CI, 1.088-8.300; $\mathrm{P}=0.034$ ). Analysis of DFS in WT patients using univariate survival analysis showed that smoking was the only associated risk factor (HR, 2.174; CI, 1.046-4.518; $\mathrm{P}=0.038$ ). Visceral pleural invasion was risk factor for OS in univariate analysis, but not in multivariate analysis. It might be because of small sample sizes.

\section{Discussion}

We performed the present study to clarify whether $E G F R$ mutation status can be considered a prognostic factor predicting the effect of PBAC and to elucidate whether there is a difference in the effect of adjuvant chemotherapy based on mutational subtype.

We found that EGFR mutation status was not predictive of OS or DFS benefit from PBAC in lung adenocarcinoma; 
A

DFS stratified according to PBAC with 19del patients

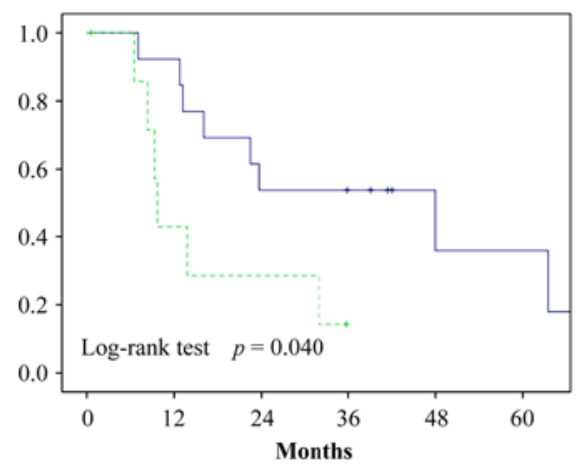

$\begin{array}{lcccccc}\text { Patients at risk } & & & & & \\ \\ \text { PBAC } & 13 & 12 & 7 & 7 & 6 & 6 \\ \text { P....... Observation } & 8 & 4 & 3 & 2 & 2 & 2\end{array}$

C

OS stratified according to PBAC with 19del patients

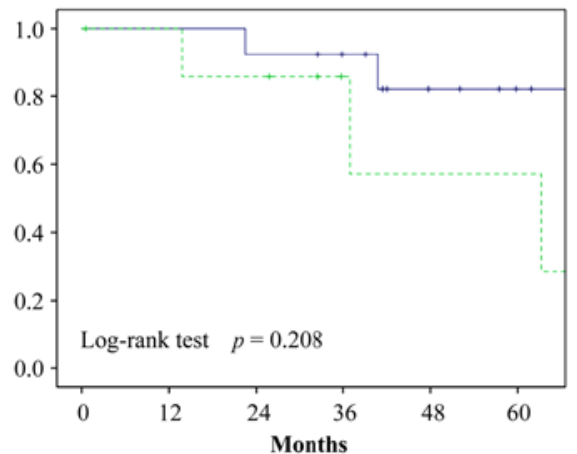

Patients at risk

$\begin{array}{lllllll}\text { PBAC } & 13 & 13 & 12 & 12 & 11 & 11\end{array}$

$\begin{array}{llllllll}\text {......... Observation } & 8 & 8 & 7 & 7 & 6 & 6\end{array}$
B

DFS stratified according to PBAC with 21L858R patients

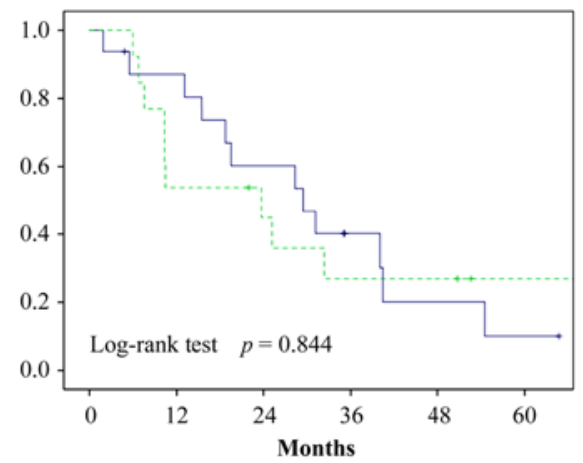

Patients at risk

\begin{tabular}{|c|c|c|c|c|c|c|}
\hline - & PBAC & 16 & 14 & 10 & 7 & 5 \\
\hline n......... & Observation & 13 & 7 & 6 & 4 & 4 \\
\hline
\end{tabular}

D

OS stratified according to PBAC with 21L858R patients

Patients at risk

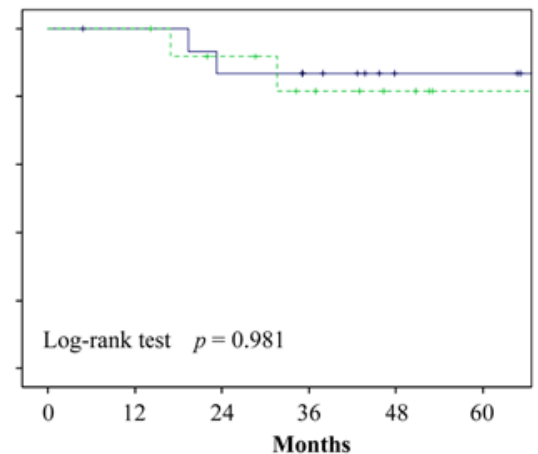

$\begin{array}{llllllll} & \text { PBAC } & 16 & 16 & 14 & 14 & 14 & 14\end{array}$

$\begin{array}{lllllll}\text { Observation } & 13 & 13 & 12 & 11 & 11 & 11\end{array}$

Figure 2. DFS curves based on (A) PBAC in patients with in-frame deletions in exon19 (19del) and (B) PBAC in patients with the point mutation L858R in exon21 (21L858R). There were statistically significant differences in the DFS rates independent of PBAC in 19del patients. Overall survival curves based on (C) PBAC in patients with 19del and (D) PBAC in patients with 21L858R. DFS, disease-free survival; PBAC, platinum-based adjuvant chemotherapy.

however, in WT patients, PBAC was a significant prognostic factor for OS. This indicates that EGFR mutation status might be considered as a predicting factor for poor effect of PBAC and MT patients might benefit less from adjuvant chemotherapy than WT patients would. In general, EGFR-TKI as first-line treatment for advanced NSCLC prolongs progression-free survival and increases the objective response rate compared with platinum doublet chemotherapy $(8,9)$. Few studies focused on the prognostic value of $E G F R$ mutation status in patients with advanced NSCLC with chemotherapy.

In this present analysis of OS, there were no statistically significant differences between MT patients with PBAC and those without PBAC. The reason for this outcome may be the effectiveness of EGFR-TKIs in MT patients in general. Prolonged survival after recurrence in both groups of MT patients might have obscured the difference in OS between the groups. Kudo et al reported that the presence of EGFR mutations is a good prognostic factor in MT patients with postoperative recurrence (10). In contrast, in WT patients, EGFR-TKIs have not been approved for the treatment of NSCLC except erlotinib and have less effectiveness than in MT patients.
EGFR positive lung cancer is effective by EGFR-TKI, and the benefits of PBAC might been diminished due to the longer treatment period after relapse compared to the time to relapse.

Instead of PBAC in MT patients whose effect may be less effective, EGFR-TKI treatment as postoperative adjuvant chemotherapy for MT patients has been investigated. Several studies suggested a possible benefit of EGFR-TKI as postoperative adjuvant chemotherapy for MT patients. In an analysis of 167 patients with resected stages I to IIIA NSCLC with EGFR mutations, patients who received EGFR-TKI treatment showed a more favorable 2 year DFS rate than an untreated group (HR, 0.53; 95\% CI, 0.28-1.03; P=0.06) (16). Another study, a single-arm, multi-institutional, prospective phase II study called the SELECT trial, showed that 100 patients with resected stages IA to IIIA NSCLC and EGFR mutations receiving adjuvant erlotinib for 2 years after standard-of-care treatment had a 2 year DFS rate of $89 \%$ with a median follow-up of 3.4 years (17).

The above studies suggest the possible benefit of EGFR-TKI adjuvant chemotherapy in MT patients. On the other hand, a randomized, double-blind, placebo-controlled phase III trial called the RADIANT study using erlotinib as adjuvant EGFR-TKI analyzed a total of 278 patients and failed to 
Table III. Univariate and Multivariate analysis of disease-free survival and overall survival.

A, All patients

\begin{tabular}{|c|c|c|c|c|c|c|c|c|}
\hline \multirow[b]{3}{*}{ Variable } & \multicolumn{4}{|c|}{ Overall survival } & \multicolumn{4}{|c|}{ Disease-free survival } \\
\hline & \multirow{2}{*}{$\begin{array}{c}\text { UVA } \\
\text { P-value }\end{array}$} & \multicolumn{3}{|c|}{ MVA } & \multirow{2}{*}{$\begin{array}{l}\text { UVA } \\
\text { P-value }\end{array}$} & \multicolumn{3}{|c|}{ MVA } \\
\hline & & Hazard ratio & $95 \% \mathrm{CI}$ & P-value & & Hazard ratio & $95 \% \mathrm{CI}$ & P-value \\
\hline Sex & 0.471 & - & - & - & 0.233 & - & - & - \\
\hline Age & 0.118 & - & - & - & 0.130 & - & - & - \\
\hline Smoking habits & 0.093 & - & - & - & 0.032 & 1.695 & $1.047-2.746$ & 0.032 \\
\hline Pathological stage & 0.186 & - & - & - & 0.216 & - & - & - \\
\hline Vascular invasion & 0.034 & 4.872 & $1.073-22.122$ & 0.04 & 0.084 & - & - & - \\
\hline Lymphatic premeation & 0.403 & - & - & - & 0.854 & - & - & - \\
\hline Viscreral pleural invasion & 0.021 & 2.000 & $0.915-4.373$ & NS $(0.082)$ & 0.036 & 1.681 & $1.038-2.723$ & 0.035 \\
\hline Tumor differentiation & 0.020 & 2.260 & $1.040-4.911$ & 0.039 & 0.709 & - & - & - \\
\hline Adjuvant chemotherapy & 0.030 & 2.519 & $1.143-5.550$ & 0.022 & 0.073 & - & - & - \\
\hline
\end{tabular}

B, Patients with EGFR wild-type

\begin{tabular}{|c|c|c|c|c|c|c|c|c|}
\hline \multirow[b]{3}{*}{ Variable } & \multicolumn{4}{|c|}{ Overall survival } & \multicolumn{4}{|c|}{ Disease-free survival } \\
\hline & \multirow{2}{*}{$\begin{array}{c}\text { UVA } \\
\text { P-value }\end{array}$} & \multicolumn{3}{|c|}{ MVA } & \multirow{2}{*}{$\begin{array}{l}\text { UVA } \\
\text { P-value }\end{array}$} & \multicolumn{3}{|c|}{ MVA } \\
\hline & & Hazard ratio & $95 \% \mathrm{CI}$ & P-value & & Hazard ratio & $95 \% \mathrm{CI}$ & P-value \\
\hline Sex & 0.987 & - & - & - & 0.319 & - & - & - \\
\hline Age & 0.489 & - & - & - & 0.920 & - & - & - \\
\hline Smoking habits & 0.227 & - & - & - & 0.038 & - & - & - \\
\hline Pathological stage & 0.433 & - & - & - & 0.872 & - & - & - \\
\hline Vascular invasion & 0.125 & - & - & - & 0.583 & - & - & - \\
\hline Lymphatic premeation & 0.526 & - & - & - & 0.500 & - & - & - \\
\hline Viscreral pleural invasion & 0.021 & 3.242 & $1.173-8.958$ & 0.023 & 0.050 & - & - & - \\
\hline Tumor differentiation & 0.085 & - & - & - & 0.290 & - & - & - \\
\hline Adjuvant chemotherapy & 0.034 & 2.928 & $1.059-8.091$ & 0.038 & 0.218 & - & - & - \\
\hline
\end{tabular}

B, Patients with EGFR mutant

\begin{tabular}{|c|c|c|c|c|c|c|c|c|}
\hline \multirow[b]{3}{*}{ Variable } & \multicolumn{4}{|c|}{ Overall survival } & \multicolumn{4}{|c|}{ Disease-free survival } \\
\hline & \multirow{2}{*}{$\begin{array}{c}\text { UVA } \\
\text { P-value }\end{array}$} & \multicolumn{3}{|c|}{ MVA } & \multirow{2}{*}{$\begin{array}{l}\text { UVA } \\
\text { P-value }\end{array}$} & \multicolumn{3}{|c|}{ MVA } \\
\hline & & Hazard ratio & $95 \% \mathrm{CI}$ & P-value & & Hazard ratio & $95 \% \mathrm{CI}$ & P-value \\
\hline Sex & 0.127 & - & - & - & 0.925 & - & - & - \\
\hline Age & 0.068 & - & - & - & 0.073 & - & - & - \\
\hline Smoking habits & 0.186 & - & - & - & 0.767 & - & - & - \\
\hline Pathological stage & 0.118 & - & - & - & 0.136 & - & - & - \\
\hline Vascular invasion & 0.172 & - & - & - & 0.025 & - & - & - \\
\hline Lymphatic premeation & 0.759 & - & - & - & 0.444 & - & - & - \\
\hline Viscreral pleural invasion & 0.558 & - & - & - & 0.433 & - & - & - \\
\hline Tumor differentiation & 0.286 & - & - & - & 0.944 & - & - & - \\
\hline Adjuvant chemotherapy & 0.505 & - & - & - & 0.287 & - & - & - \\
\hline Mutational status & 0.343 & - & - & - & 0.955 & - & - & - \\
\hline
\end{tabular}

-, Not included in MVA. EGFR, epidermal growth factor receptor; NS, no statistical difference; MT, mutation-positive; UVA, uni-variate analysis; MVA, multi-variate analysis; CI, confidence interval. 
demonstrate a DFS benefit of erlotinib in EGFR mutation-positive patients (18).

In the analysis of subtypes, 19del patients with PBAC showed significantly longer DFS than 19del patients without PBAC, but 21L858R patient groups showed no statistically significant difference in DFS. There are likely differences in clinical and biological features between patients with 19del and those with L858R. It was reported that the patterns of both $E G F R$ amplification and EGFR autophosphorylation were shown to differ between cell lines harboring the two most common EGFR mutation types of 19del and L858R mutation (19). Several studies have reported data regarding these two common EGFR mutations. In an analysis of MT patients receiving no EGFR-TKI therapy, those with the 19 del mutation had worse survival than those with the L858R mutation (11). Yamashita et al reported that among NSCLC patients receiving platinum-based chemotherapy, those with exon 19 deletion have a longer PFS and OS. This result supported the significant effect of PBAC in DFS rates in 19 del patient (20).

A multicenter, international, open-label, exploratory, randomized controlled trial called the LUX-Lung7 showed a difference in OS between patients with the common EGFR mutations (21) and suggested that 19del patients might be more sensitive to EGFR-TKIs than those with 21L858R.

On the basis of previous reports, we speculated that the number of patients with the 19 del mutation who remain at the micro-metastasis stage after complete cancer resection would be larger than those with the 21L858R mutation. In terms of postoperative recurrence, EGFR-TKIs showed good effectiveness among 19del patients $(16,21)$. We found a statistically significant difference in DFS but not OS between 19del patients with PBAC and those without PBAC.

We must acknowledge three limitations in the present study. First, the number of patients was small and data analysis may not have been maximally effective. In future studies, we plan to collect more data regarding surgically resected adenocarcinoma with pathologically confirmed lymph node metastasis. Second, this study was retrospective and single institutional. Third, we excluded patients with unknown EGFR mutation status; even though the number of such excluded patients was small, it may have contributed to selection bias.

In the present study, compared with patients with WT, EGFR mutation-positive patients showed less influence of PBAC on improvement of survival rate. PBAC might not be necessary for Mt patients with pathological stage II/III lung adenocarcinoma

On the basis of the EGFR mutation subtype, patients with the 19 del mutation undergoing PBAC showed significantly more favorable DFS than those without PBAC. It may therefore be necessary to consider postoperative strategy based on the presence of EGFR mutations and their subtype in patients with completely resected adenocarcinoma.

\section{Acknowledgements}

Not applicable.

\section{Funding}

The present study was supported by AMED [grant no. JP17ck0106295].

\section{Availability of data and materials}

The datasets used and/or analyzed during the present study are available from the corresponding author on reasonable request.

\section{Authors' contributions}

$\mathrm{YK}, \mathrm{TeO}$ and NI designed the study; YK performed the research, with the assistance of TeO, KI, SM, JM, KY, MH, MK, NK TaO and JM. YK and TeO analyzed the data. YK and TOK generated the figures and wrote the paper. TeO and NI revised the figures and critically revised the manuscript for important intellectual content. All authors have read and approved the manuscript.

\section{Ethics approval and consent to participate}

The present study was approved by the ethics committee of the Tokyo Medical University (approval number: 2016-167).

\section{Patient consent for publication}

Not applicable.

\section{Competing interests}

The authors declare that they have no competing interests.

\section{References}

1. Arriagada R, Bergman B, Dunant A, Le Chevalier T, Pignon JP and Vansteenkiste J; International Adjuvant Lung Cancer Trial Collaborative Group: Cisplatin-based adjuvant chemotherapy in patients with completely resected non-small-cell lung cancer. N Engl J Med 350: 351-360, 2004.

2. NSCLC Meta-analyses Collaborative Group, Arriagada R, Auperin A, Burdett S, Higgins JP, Johnson DH, Le Chevalier T, Le Pechoux C, Parmar MK, Pignon JP, et al: Adjuvant chemotherapy, with or without postoperative radiotherapy, in operable non-small-cell lung cancer: Two meta-analyses of individual patient data. Lancet 375: 1267-1277, 2010.

3. Strauss GM, Herndon JE II, Maddaus MA, Johnstone DW, Johnson EA, Harpole DH, Gillenwater HH, Watson DM, Sugarbaker DJ, Schilsky RL, et al: Adjuvant paclitaxel plus carboplatin compared with observation in stage IB non-small-cell lung cancer: CALGB 9633 with the cancer and leukemia group B, radiation therapy oncology group, and north central cancer treatment group study groups. J Clin Oncol 26: 5043-5051, 2008.

4. Winton T, Livingston R, Johnson D, Rigas J, Johnston M, Butts C, Cormier Y, Goss G, Inculet R, Vallieres E, et al: Vinorelbine plus cisplatin vs. observation in resected non-small-cell lung cancer. N Engl J Med 352: 2589-2597, 2005.

5. Douillard JY, Rosell R, De Lena M, Carpagnano F, Ramlau R, Gonzáles-Larriba JL, Grodzki T, Pereira JR, Le Groumellec A, Lorusso V, et al: Adjuvant vinorelbine plus cisplatin versus observation in patients with completely resected stage IB-IIIA non-small-cell lung cancer [Adjuvant Navelbine International Trialist Association (ANITA)]: A randomised controlled trial. Lancet Oncol 7: 719-727, 2006.

6. Pignon JP, Tribodet H, Scagliotti GV, Douillard JY, Shepherd FA, Stephens RJ, Dunant A, Torri V, Rosell R, Seymour L, et al: LACE Collaborative group, lung adjuvant cisplatin evaluation: A pooled analysis by the LACE collaborative group. J Clin Oncol 26: 3552-3559, 2008.

7. Waller D, Peake MD, Stephens RJ, Gower NH, Milroy R, Parmar MK, Rudd RM and Spiro SG: Chemotherapy for patients with non-small cell lung cancer: The surgical setting of the big lung trial. Eur J Cardiothorac Surg 26: 173-182, 2004. 
8. Rosell R, Carcereny E, Gervais R, Vergnenegre A, Massuti B, Felip E, Palmero R, Garcia-Gomez R, Pallares C, Sanchez JM, et al: Erlotinib versus standard chemotherapy as first-line treatment for European patients with advanced EGFR mutation-positive non-small-cell lung cancer (EURTAC): A multicentre, open-label, randomised phase 3 trial. Lancet Oncol 13: 239-246, 2012.

9. Mok TS, Wu YL, Thongprasert S, Yang CH, Chu DT, Saijo N, Sunpaweravong P, Han B, Margono B, Ichinose Y, et al: Gefitinib or carboplatin-paclitaxel in pulmonary adenocarcinoma. N Engl J Med 361: 947-957, 2009.

10. Kudo Y, Shimada Y, Saji H, Kato Y, Yoshida K, Matsubayashi J, Nagase S, Kakihana M, Kajiwara N, Ohira T, et al: Prognostic factors for survival after recurrence in patients with completely resected lung adenocarcinoma: Important roles of epidermal growth factor receptor mutation status and the current staging system. Clin Lung Cancer 16: e213-221, 2015.

11. Shigematsu H, Lin L, Takahashi T, Nomura M, Suzuki M, Wistuba II, Fong KM, Lee H, Toyooka S, Shimizu N, et al: Clinical and biological features associated with epidermal growth factor receptor gene mutations in lung cancers. J Natl Cancer Inst 97: 339-346, 2005.

12. Isaka T, Yokose T, Ito H, Nagata M, Furumoto H, Nishii T, Katayama K, Yamada $K$, Nakayama $H$ and Masuda $M$ : Correlations between the EGFR mutation status and clinicopathological features of clinical Stage I lung adenocarcinoma. Medicine (Baltimore) 94: e1784, 2015.

13. Sobin LH, Gospodarowicz MK, Wittekind C, International Union against Cancer, TNM Classification of Malignant Tumours. 7th ed. Wiley-Blackwell Chichester, UK; Hoboken, NJ; 2010.

14. Yatabe Y,Hida T, Horio Y,Kosaka T, Takahashi T and Mitsudomi T: A rapid, sensitive assay to detect EGFR mutation in small biopsy specimens from lung cancer. J Mol Diagn 8: 335-341, 2006.

15. Yoshida K, Yatabe Y, Park JY, Shimizu J, Horio Y, Matsuo K, Kosaka T, Mitsudomi T and Hida T: Prospective validation for prediction of gefitinib sensitivity by epidermal growth factor receptor gene mutation in patients with non-small cell lung cancer. J Thoracic Oncol 2: 22-28, 2007.
16. JanjigianYY,ParkBJ,ZakowskiMF,LadanyiM,PaoW,D'AngeloSP Kris MG, Shen R, Zheng J and Azzoli CG: Impact on disease-free survival of adjuvant erlotinib or gefitinib in patients with resected lung adenocarcinomas that harbor EGFR mutations. J Thorac Oncol 6: 569-575, 2011.

17. Pennell NA, Neal JW, Chaft JE, Azzoli CG, Janne PA, Govindan R, Evans TL, Costa DB, Rosovsky RP, Wakelee HA, et al: SELECT: A multicenter phase II trial of adjuvant erlotinib in resected early stage EGFR mutation-positive NSCLC. J Clin Oncol 32: 7514-7514, 2014

18. Kelly K, Altorki NK, Eberhardt WE, O'Brien ME, Spigel DR Crinò L, Tsai CM, Kim JH, Cho EK, Hoffman PC, et al: Adjuvant erlotinib versus placebo in patients with stage IB-IIIA non-small-cell lung cancer (RADIANT): A randomized, double-blind, Phase III trial. J Clin Oncol 33: 4007-4014, 2015.

19. Okabe T, Okamoto I, Tamura K, Terashima M, Yoshida T, Satoh T, Takada M, Fukuoka M and Nakagawa K: Differential constitutive activation of the epidermal growth factor receptor in non-small cell lung cancer cells bearing EGFR gene mutation and amplification. Cancer Res 67: 2046-2053, 2007.

20. Yamashita F, Azuma K, Yoshida T, Yamada K, Kawahara A, Hattori S, Takeoka H, Zaizen Y, Kawayama T, Kage M and Hoshino T: Prognostic value of EGFR mutation and ERCC1 in patients with non-small cell lung cancer undergoing platinum-based chemotherapy. PLoS One 8: e71356, 2013.

21. Park K, Tan EH, O'Byrne K, Zhang L, Boyer M, Mok T, Hirsh V, Yang JC, Lee KH, Lu S, et al: Afatinib versus gefitinib as first-line treatment of patients with EGFR mutation-positive non-small-cell lung cancer (LUX-Lung 7): A phase 2B, open-label, randomised controlled trial. Lancet Oncol 17: 577-589, 2016.

This work is licensed under a Creative Commons

Attribution-NonCommercial-NoDerivatives 4.0 International (CC BY-NC-ND 4.0) License. 